\title{
BLENDED LEARNING: A NEW APPROACH TO TEACH BALLET TECHNIQUE FOR UNDERGRADUATE STUDENTS
}

\author{
Dr. Manal BAYYAT \\ ORCID: 0000-0002-0151-5810 \\ School of Physical Education University of Jordan \\ Amman, JORDAN
}

Received: 06/03/2019 Accepted: 29/07/2019

\begin{abstract}
This study aims to investigate and compare the effect of the Blended Learning (BL) approach to Face to Face (FTF) teaching method on students' level of performance and sport participation motivation level. It is a qualitative study using the quasi-experimental method and applying the pre-test/post-test two-groups design model. The participants of this study were 40 female undergraduate students of School of Physical Education/University of Jordan. They were beginners enrolled in ballet classes with no previous experience in ballet; 18 students attended the FTF ballet class (control group), and 22 students attended the BL ballet class (experimental group). Skill performance tests and Sport participation Motivation Scale SMS-28 were used to collect the study's pre and post data. The data were then analyzed using descriptive analysis. The results of this study revealed no significant differences between teaching strategies in relation to students' level of performance. On the other hand, significant differences occurred in post-tests of students' motivation level in favor of the BL group. All intrinsic and extrinsic motivation subscales except for amotivation were significantly different in favor of BL classes. In conclusion, BL proved to be an efficient and convenient methodology in terms of enhancing students' level of performance and boost their motivation for sports participation.
\end{abstract}

Keywords: Blended Learning, ballet dance, teaching methodology, higher education, distance education.

\section{INTRODUCTION}

Pedagogy is rapidly changing according to the students' needs. It is important that we develop the best practice in academia (Pizzi, 2014). Higher education has been actively encouraged to find more effective and flexible delivery models. Teachers aim to provide all students with access to quality learning experiences yet also meet institutional imperatives for efficiency and accountability (George-Walker, \& Keeffe, 2010).

BL become known as one of the most popular pedagogical concepts at the beginning of 2000 (Güzer, \& Caner, 2014). It is based on the guidance of different theoretical studies to meet the needs of different learners, learning environments, and learning goals (Stubbs, Martin, \& Endlar, 2006). It is possible to transform traditional modules of teaching into problem-based Blended Learning using a social constructivist approach, and moreover reduce lecturing time, support repetition and support educational differentiation (Dalsgaard \& Godsk, 2007).

$\mathrm{BL}$ is considered as one of the most important pedagogical designs, It is defined by Bourne, Harris, and Mayadas (2005) as an optimal combination of Face to Face (FTF) and online education; The online component needs careful planning according to student's needs, the capacity of the institutions and the subject matter to optimize the use of active learning strategies (Dos, 2014). BL exposes students to an authentic, meaningful learning experience with greater feedback, flexible, and active learning (Bonk, Olson, Wisher \& Orvis, 2002).

BL can potentially improve learning and satisfaction of instructors and students at a reasonable cost (Bourne et al., 2005; Smith, 2005; Pizzi, 2014). Implementing the BL model for an undergraduate course revealed students' overall satisfaction and positive perception. They were satisfied with interactive content and online 
quizzes. Moreover, student-centered practices, particularly collaborative projects, and student-led activities were the most salient themes for successful instructional strategies (Dos, 2014; Tamim, 2018).

Computer network technology has brought huge changes to people's life since the beginning of the 21st century (Le, 2011; Mitchell \& Forer, 2010) recognized information and communication technologies as providers of learning benefits, alongside traditional mechanisms such as lectures. Online material had to be interactive, engaging, and complement the FTF sessions (Keogh, Gowthorp \& McLean, 2017).

A Moodle is an example of an open source software package used in the BL model. It makes teaching activities become more vivid and teaching achievements more outstanding through a model of interaction among learners (Zhou, Zhou, \& Zhou, 2017). Moodle platform can configure online forums, homework, and other curriculum activities. Also, it optimizes the teaching management while enriching the communication modes in the teaching process, in which forum modules, seminar module, and chat module provide a variety of exchanging platform for students and teachers, as well as students and students (Feng, 2018).

Accordingly, BL approach uses a virtual learning environment to deliver learning resources and activities to support learners using a distance learning model. Online tracking can also help to target 'at risk' learners quickly (Hughes, 2007).

After analyzing 355 distance education comparative studies, Russel, (1999) claimed that no one method of delivering instruction is more effective than any other. Later, Shen, Chung, Challis, and Cheung (2007) revealed in a study for more than four years for 2000 students no significant differences between BL and FTF instructional methods.

Motivation can influence when to choose to learn, how we learn, and what we learn (Schunck, Pintrich \& Meece, 2008). It is a key factor for successful e-learning (Waheed, Kaur, Ain, \& Hussain, 2016). Motivated learners enjoy and adopt new learning approaches, undertake challenging activities while actively engaged, and demonstrate enhanced performance, persistence, and creativity (Schunck et al., 2008; Shroff \&Vogel, 2009).

Self Determination Theory provides an analytical tool for discovering the complexity of motivation in an online context (Hartnett, George, \& Dron, 2011). The theory explains intrinsic (IM) and extrinsic motivation (EM) as two main types of motivation based on different activities that lead to action. Communication with peers, relatedness, and autonomy stimulate intrinsic motivation, while external benefits, facilities, and rewards excite extrinsic motivation (Ryan and Deci, 2000). Intrinsic and extrinsic motivation are highly sensitive to situational influence (Hartnett et al., 2011). Shroff \& Vogel (2009) stated that online students are more intrinsically motivated than their colleagues in traditional classes. BL enhance students' metacognitive processes, essential for the advancement of the self-determined learner, as well as flexibility, responsibility, and independence (Bonk et al., 2002).

George-Walker \& Keeffe, (2010) argued that BL is a learner-centered offers endless successful combinations - as many as there are individual students. Students engage, also develop their skills as self-determined learners; reflective, self-directed, and self-regulating. Furthermore, the role of the instructor in developing a BL course is to offer multiple means of representation, expression, and engagement and to support students in the creation of their own individualized blend.

Ballet classes are taught in colleges, universities, and schools. They are also offered in dance, physical education, theatre, music, or other departments. It is a Western classical dance form and performing art that is over four centuries old (Kassing, 2013). Merriam-Webster defines ballet as a theatrical art form using dancing, music, and scenery to convey a story, theme, or atmosphere (Ballet, n.d.).

Beginning ballet is a foundational course for becoming a dancer or choreographer. Students in academic ballet courses learn ballet technique, apply movement principles to class work, view ballet performances, and study ballet as a performing art. Standard ballet training is almost entirely teacher-led and gives the student little opportunity for communication. Teacher's instructions only focus on the accuracy of correct technical exercises (Wang, \& Wang, 2017).

Similar to the methods of studying other art forms, students learn the vocabulary and technical terms of ballet, explore its history, gain a sense of the dance form's aesthetics, and gain other supporting knowledge such as injury prevention and the requirements and expectations of a dancer. Testing entails both performance and written assignments (Kassing, 2013). 
Dance educators discussed the pedagogical philosophies and challenges. Khoury, Martin, \& Rowe (2013) conversed the dominant models and meanings of teaching and learning dance, along with the demand for tolerance towards different ideas and approaches.

In an attempt to enhance the teaching process, Online interface was created containing controls for automatic composition and the 3D display. The digital system provides a creative resource for new enchainements usable in ballet education by teachers and students (Umino, Longstaff, \& Soga, 2009). Also, The European project Open Dance and the 3D simulation of folk dances on the web provided a learning framework for folk dances. Students interacted with the platform and observed how the virtual dance teachers perform. The evaluation of the system indicates that the increased usability of this approach enhances the learning process. (Magnenat-Thalmann, Protopsaltou, \& Kavakli, 2007).

In spite of Jordan's limited financial and human resources, higher education plays an effective role in promoting Jordanian citizen's economic, social, and knowledge level. In the region as a whole, Jordan's educational role has been known for the high quality of its educational system ("Brief on Higher Education Sector in Jordan," 2019). In coherence, the University of Jordan has adopted the BL approach in teaching. A step forward in the field of education, in an attempt to keep up with the educational revolution in the world. Academic staff are encouraged to use the BL approach. Gradually the number of BL courses are increasing. The majority of them are theoritical courses. At the School of Physical education/ University of Jordan, Ballet course is an optional requirement for female students. It is a practical subject that pays more attention to FTF gesture and post in the process of teaching and learning. This traditional concept restricts the popularization of computer networks in sports learning, leading to its backwardness in informatization compared with other subjects (Li \& Wei, 2011).

\section{PURPOSE OF THE STUDY}

$\mathrm{BL}$ is in its early stages in the University of Jordan. It is implemented in several theoretical courses and few practical courses. In review of the related literature highlighting the positive effect of BL on students' learning outcomes in practical courses, the need of studies that evaluate students' learning outcomes and their motivation in BL in practical sports courses in general. Ballet subject was chosen to implement the BL approach at the School of Physical Education /University of Jordan.

This study aims to evaluate and compare the effect of the BL to the conventional teaching method (FTF) on students' level of performance and sport participation motivation level. FTF (FTF) group was selected as the control group. While the $\mathrm{BL}$ group was chosen to be the experimental group. Thus, the purpose of this study is to evaluate and compare the effect of the BL (BL) approach to FTF (FTF) teaching method on students' level of performance and sport participation motivation level.

To fulfill the purpose of the study, the research seeks to test the following hypotheses;

H01: There is no statistically significant difference between post-test scores of both control (FTF group) and experimental group (BL group) of students' level of performance in ballet skills at the level of $a \leq 0.05$.

H11: There is a statistically significant difference between post-test scores of both control (FTF group) and experimental group (BL group) of students' level of performance in ballet skills at the level of $a \leq 0.05$.

H02: There is no statistically significant difference between post-test scores of both control (FTF group) and experimental group (BL group) of students' motivation type according to selfdetermination theory at the level of $a \leq 0.05$.

H12: There is a statistically significant difference between post-test scores of both control (FTF group) and experimental group (BL group) of students' motivation type according to self-determination theory at the level of $\mathrm{a} \leq 0.05$. 


\section{The Importance of the Study:}

For scholars and educators; It helps them understand the effect of BL on the educational process and inspires them to implement such an approach in the future.

For the students; It encourages students to enroll in BL courses, where learning is more flexible, self-centered and motivational.

For stakeholders: to adopt such new learning approaches that utilize technology and facilitate positive globalization.

\section{METHOD}

\section{Research Model}

This is a qualitative study using the quasi-experimental method and applying the pretest/ posttest twogroups design model. During the experiment, a control group will be taught using the traditional FTF method. While, the experimental group will be taught using the BL approach.

The independent variables: FTF and BL Teaching strategies.

The dependent variables: The ballet skills performance level and motivation type for sports participation according to self-determination theory.

\section{Participants}

Two ballet classes held in the first and second semester of the academic year 2017/2018 at the School of Physical Education/University of Jordan were chosen to conduct this study. A purposive sample of all students enrolled in both classes was assigned. It consisted of 40 female undergraduate students enrolled in both ballet classes. Ages ranged between 19-21years $(M=19.7 \pm 0.09)$. All students had no previous experience related to ballet skills. Table 1 shows that both groups were beginners, and no significant differences occurred in their motivation level at subscales level or in total.

Table 1. Mean, standard deviation and t-test in the level of performance and motivation subscales for the sample of both control (FTF) and experimental group (BL)

\begin{tabular}{|c|c|c|c|c|c|}
\hline & Group & Mean & SD & $t$-Test & sig \\
\hline Level of Performance & $\begin{array}{c}\text { FTF } \\
\text { BL }\end{array}$ & $\begin{array}{l}2.06 \\
2.03\end{array}$ & $\begin{array}{l}.73 \\
.66\end{array}$ & .18 & .86 \\
\hline Motivation Subscales & Group & Mean & Std. Dev & $\mathrm{t}$-Test & sig \\
\hline IM - To Know & $\begin{array}{c}\text { FTF } \\
\text { BL }\end{array}$ & $\begin{array}{l}3.25 \\
3.33\end{array}$ & $\begin{array}{l}.62 \\
.49\end{array}$ & .55 & .58 \\
\hline IM - To Accomplish & $\begin{array}{c}\text { FTF } \\
\text { BL }\end{array}$ & $\begin{array}{l}3.48 \\
3.56\end{array}$ & $\begin{array}{l}.23 \\
.82\end{array}$ & .51 & .61 \\
\hline IM - To Experience & $\begin{array}{c}\text { FTF } \\
\text { BL }\end{array}$ & $\begin{array}{l}3.34 \\
3.29\end{array}$ & $\begin{array}{c}.50 \\
0.56\end{array}$ & .36 & .71 \\
\hline Intrinsic Motivation & $\begin{array}{c}\text { FTF } \\
\text { BL }\end{array}$ & $\begin{array}{l}3.35 \\
3.39\end{array}$ & $\begin{array}{l}.30 \\
.62\end{array}$ & .41 & .68 \\
\hline Identified Regulation & $\begin{array}{c}\text { FTF } \\
\text { BL }\end{array}$ & $\begin{array}{l}3.55 \\
3.61\end{array}$ & $\begin{array}{l}.46 \\
.86\end{array}$ & .33 & .73 \\
\hline Introjected Regulation & $\begin{array}{c}\text { FTF } \\
\text { BL }\end{array}$ & $\begin{array}{l}3.63 \\
3.71\end{array}$ & $\begin{array}{l}.59 \\
.68\end{array}$ & .48 & .62 \\
\hline External Regulation & $\begin{array}{c}\text { FTF } \\
\text { BL }\end{array}$ & $\begin{array}{l}3.60 \\
3.86\end{array}$ & $\begin{array}{l}.57 \\
.71\end{array}$ & 1.59 & .11 \\
\hline Extrinsic Motivation & $\begin{array}{c}\text { FTF } \\
\text { BL }\end{array}$ & $\begin{array}{l}3.59 \\
3.72\end{array}$ & $\begin{array}{l}.35 \\
.53\end{array}$ & 1.12 & .26 \\
\hline Amotivation & $\begin{array}{c}\text { FTF } \\
\text { BL }\end{array}$ & $\begin{array}{c}3.29 \\
3.5\end{array}$ & $\begin{array}{l}.61 \\
.65\end{array}$ & 1.29 & .21 \\
\hline Total & $\begin{array}{c}\text { FTF } \\
\text { BL }\end{array}$ & $\begin{array}{c}3.31 \\
3.4\end{array}$ & $\begin{array}{l}.46 \\
.51\end{array}$ & .71 & .47 \\
\hline
\end{tabular}

Note. ${ }^{*} p<.05$ 


\section{Assignment of the Control and Experimental Group}

Both Ballet classes were held in the first and second semester of the academic year 2017/2018 at the School of Physical Education/University of Jordan, The control and experimental groups were assigned purposely. Eighteen students attended the FTF ballet class (control group) on the first semester of the academic year 2017/2018, and 22 students attended the BL ballet class (experimental group) on the second semester of the academic year 2017/2018. The participants signed an approval consent to be part of this study. The ethical committee of the university approved the research protocol. Statistical analysis was conducted using the pretests data of study variables to prove the equilivancy of both control and experimental group of the study at the beginning of the ballet courses.

\section{Procedure}

Ballet class is an optional practical course for female students at the School of the Physical Education/ University of Jordan. It is a two - credit hour course, yet students attend a one-hour class three times a week for 14 weeks (academic semester). The content and outcomes of Ballet courses for both control and experimental groups were the same. Each course included; An introduction to ballet, preparing for class, safety and health, learning and performing ballet technique, basics of ballet technique, at the barre exercises, in the centre exercises, Allegro, and reverence (Kassing, 2013).

To conclude this study two ballet courses, delivered by the same instructor, was assigned;

The first ballet course applied the FTF approach of teaching (the control group). During which all ballet classes taught throughout the 14 weeks of the course were FTF. The instructor was responsible for delivering the course content to the students, warming up, techniques, corrections, feedback, and music. Sometimes students held responsible for minor warming up and doing routine techniques such as stretching and arms and feet positions. All learning activities and assessments took place in the classroom. The FTF course was conducted during the first semester of the academic year 2017/2018, it started in September 2017 and was finalized in December 2017.

The second ballet course applied the BL approach (the experimental group). This course was the first ballet course ever taught using the $\mathrm{BL}$ approach in the history of the University of Jordan. It was conducted differently than the FTF course; Two classes a week were FTF on Sundays and Tuesdays, while the third class was an online class on Thursdays.

On the first week of the semester, the students were presented to the BL approach in general. The online learning platform used during the BL course was the e-Learning Moodle type administered by ICT administrators at the University of Jordan. Demonstrations of the efficient use of the Moodle and application programs such as You Tube, Microsoft office and the online learning platform were performed at the computer lab of the School of Physical Education. A student could log in to the Moodle with their campus username and password reaching the systematically structured learning materials. Some ballet skills and exercises were delivered during the two FTF classes while others were offered as web links through the e-learning Moodle. Web libs were educational ballet, tutorial videos, musical plays, and ballet performances through the Moodle. It included information about each exercise, step, position, or pose, including notes for correct performance; photos of positions and poses; and video clips of exercises and steps. Students were expected to watch the videos, learn, and practice the skills assigned, complete assignments, and practice routines. Students were encouraged to use search engines to find out more about specific skills and submit their assignment on the Moodle. Sometimes they were asked to upload their routine as a video. Skills learned during the online class would be revised, practiced, and enriched along with the other skills during FTF classes. The BL was conducted during the second semester of the same academic year 2017/2018. The course started in February 2018 and was finalized in May 2018. 


\section{Data Collection and Analysis}

\section{The Tests and Scale}

Skill/performance tests and sport participation motivation scale SMS-28 were used to collect the study's pre and post data.

\section{Students' level of performance tests}

To examine the first hypothesis of the study, "There is no statistically significant difference between post-test scores of both control (FTF group) and experimental group (BL group) of students' level of performance in ballet skills at the level of $a \leq 0.05$." Skill/performance tests were developed to assess students' pre and post level of skills/performance; these were the mid-term and final evaluation tests.

The mid-term evaluation test was used as a pre-test to assess participants' skill level for both the control and experimental groups at the beginning of the study. While a total of mid and final term exams' grades was considered as the post-test to assess students' level of performance at the end of the study for both groups

The mid-term test assessed students' ability to perform fundamental ballet techniques. The targeted skills were; arm positions, feet positions, demi plie, pointe tendu, battement tendu, releve, saute and reverence. Each skill was graded out of 2 as follows; 2 for excellent performance, 1 for adequate performance, 0 for performance that needs major improvement. The total grade of the mid-term exam was 32 .

The final exam included phraseology (connecting basic movements into an artistic phrase) following certain rhythm or tempo with the flow of movement and coordination between legs and arms movements. All students' performance was assessed according to a dance performance evaluation rubric. The rubric assessed each students' phraseology, technical skills, performance skills, use of space and levels and rhythm/tempo and appearance. Each skill/performance was graded out of 3 as follows; 3 for creativity, 2 for excellent performance, 1 for adequate performance, 0 for performance that needs major improvement. The total grade of the final exam was 18 .

A total grade of mid-term and final exams was calculated and divided by 10. Final grades ranged from Excellent 9-10 points, Good 7-8 points, fair 5-6 points, partial 3-4 points, and minimal 1-2 point.

\section{Validity and reliability of the performance tests}

These tests were reviewed by three experts in the field of dance and monitoring and evaluation to determine the content and construct validity of the tests. The experts agreed that the tests included appropriate criteria and that they were valid with minor corrections, the content validity (level of agreement) was over $\% 90$ for all items. After taking their feedback into consideration, the final version of the tests was completed (Appendix 1).

To examine the reliability of the mid-term test. A group of 10 students from the control group were tested on the 6th week of the course and re-tested after eight days. The results were tested for reliability using Cronbach Alpha coefficient; correlation value was 0.85 . Likewise, to assess the reliability of the final exam. A group of 10 students from the control group were tested on the 12 th week of the course and re-tested after eight days. The Cronbach Alpha's results were also acceptable 0.87.

Thus, both tests had proved to be valid and reliable and could be used to fulfill this study.

In advance of their performance exam, students were encouraged to practice the required combinations. Ballet movements should become embedded in their movement and intellectual memory. To acquire this level of understanding, students were advised to do the following steps:

1. Practice their routine by themselves until they feel confident.

2. Execute their routine facing the mirror and do a self-check for correctness.

3. Practice their routine the combinations away from the mirror and do a self-check.

4. Concentrate on the specific areas that need attention.

5. Practice their routine with a partner. Share feedback and share areas to review (Kassing, 2013). 
To examine the second hypothesis of the study, "There is no statistically significant difference between post-test scores of both control (FTF group) and experimental group (BL group) of students' motivation type according to self-determination theory at the level of $a \leq 0.05$." we must understand students' type of motivation for learning Ballet skills in the BL course compared to their colleagues' in FTF ballet course. An Arabic version of the Sport Motivation Scale (SMS-28) was adapted and used to measure the different types of motivation proposed by the self- determination theory. The SMS-28 scale assesses three types of motivation: intrinsic, extrinsic, and amotivation. Both intrinsic and extrinsic motivation is reflected through three subscales;

The Intrinsic motivation (IM) was reflected in the scale through three subscales:

1. IM to Know; engaging in an activity for the saatisfaction and the pleasure that one experiences while learning, exploring, or trying to understand something new.

2. IM - To Accomplish; engaging in an activity for the pleasure and satisfaction experienced when one attempts to accomplish or create something — trying to master certain difficult training techniques to experience personal satisfaction.

3. IM - To Experience; engaging in an activity to experience stimulating sensations (e.g., sensory pleasure, aesthetic experiences, as well as fun and excitement) derived from one's engagement in the activity) (Weinberg \& Gould, 2011).

Extrinsic motivation (EM) was also reflected in the scale through three subscales:

1. Identification Regulation; participating in sport because they feel their involvement contributes to a part of their growth and development as a person),

2. Introjection Regulation; participating in sports because they feel pressure to be in good shape for aesthetic reasons and feel embarrassed or ashamed when they are not in the best form.

3. External Regulation; participating in sport to receive praise from their coach or because they feel urged to do so by their parents are motivated by external regulation. In this case, the sport is performed not for fun but to obtain rewards (e.g., praise) or to avoid negative consequences (e.g., criticisms from parents) (Deci \& Ryan, 2000) (Ntoumanis, N. A, 2001).

Amotivation; reflects individuals who do not perceive contingencies between their actions and the outcomes of their actions. They experience feelings of incompetence and lack of control (Deci \& Ryan, 2000). They are neither intrinsically motivated nor extrinsically motivated. When athletes are in such a state, they no longer identify any good reasons for why they continue to train. Eventually, they may even decide to stop practicing their sport.

The SMS-28 scale answered the question of "Why do you practice your sport? The answers of the question of the scale were rated on a seven-point Likert type scale from (1) (Does not correspond at all) to (7) (correspond exactly), with a mid point of (4) for the (correspond moderately).

This scale was tested for validity, reliability, and objectivity (see Bayyat, Almoghrabi, and Ay, 2016).

The SMS -28 scale was completed at the beginning and the end of the study by both groups.

\section{Procedures}

Control group and experimental group were assigned.

Participants were assigned and approvals of their participation was checked.

Pre tests for both groups were done using the mid-term test at the beginning of each course.

All participants filled the SMS (28) scale at the beginning of each course.

The control group were taught using the traditional teaching method (FTF).

The experimental group were taught using the BL approach.

All participants were evaluated using the performance tests at mid and end of each course, and a total grade was calculated. 
In advance of their performance exam, students were encouraged to practice the required combinations. Ballet movements should become embedded in their movement and intellectual memory. To acquire this level of understanding, students were advised to do the following steps:

1. Practice their routine by themselves until they feel confident.

2. Execute their routine facing the mirror and do a self-check for correctness.

3. Practice their routine the combinations away from the mirror and do a self-check.

4. Concentrate on the specific areas that need attention.

5. Practice their routine with a partner. Share feedback and share areas to review (Kassing, 2013).

Students answered the SMS (28) scale at the end of each course.

\section{Statistical Analysis}

Descriptive analysis and t-tests were conducted using SPSS software to investigate the hypotheses of the study.

\section{FINDINGS}

The results will be presented in the same order as the hypotheses of the study.

H01: There is no statistically significant difference between post-test scores of both control (FTF group) and experimental group (BL group) of students' level of performance in ballet skills at the level of $a \leq 0.05$.

The level of performance of all students revealed statistically significant differences between the mean scores of pre and post-tests of the control group in favor of post-tests, as shown in Table 2, Figure 1.

Table 2. Mean, standard deviation and t-test in pre and post-level of the performance of the control group (FTF)

\begin{tabular}{ccccccc}
\hline Level of Performance & Test & Mean & SD & t-Test & sig \\
\hline \multirow{2}{*}{ FTF } & Pre & 2.06 & .73 & 19.81 & $.000^{*}$ \\
& Post & 7 & 1.14 & & & \\
\hline
\end{tabular}

Note. ${ }^{*} p<.05$

Also, results showed statistically significant differences between the mean scores of pre and post-tests of the experimental groups in favor of post-tests, as shown in Table 3, Figure 1.

Table 3. Mean, standard deviation, and t-test in pre and post-level of the performance of the experimental group (BL).

\begin{tabular}{cccccc}
\hline Level of Performance & Test & Mean & SD & t-Test & sig \\
\hline \multirow{2}{*}{ BL } & Pre & 2.03 & .66 & \multirow{2}{*}{20.06} & $.000^{*}$ \\
\hline
\end{tabular}

Note. ${ }^{*} p<.05$ 


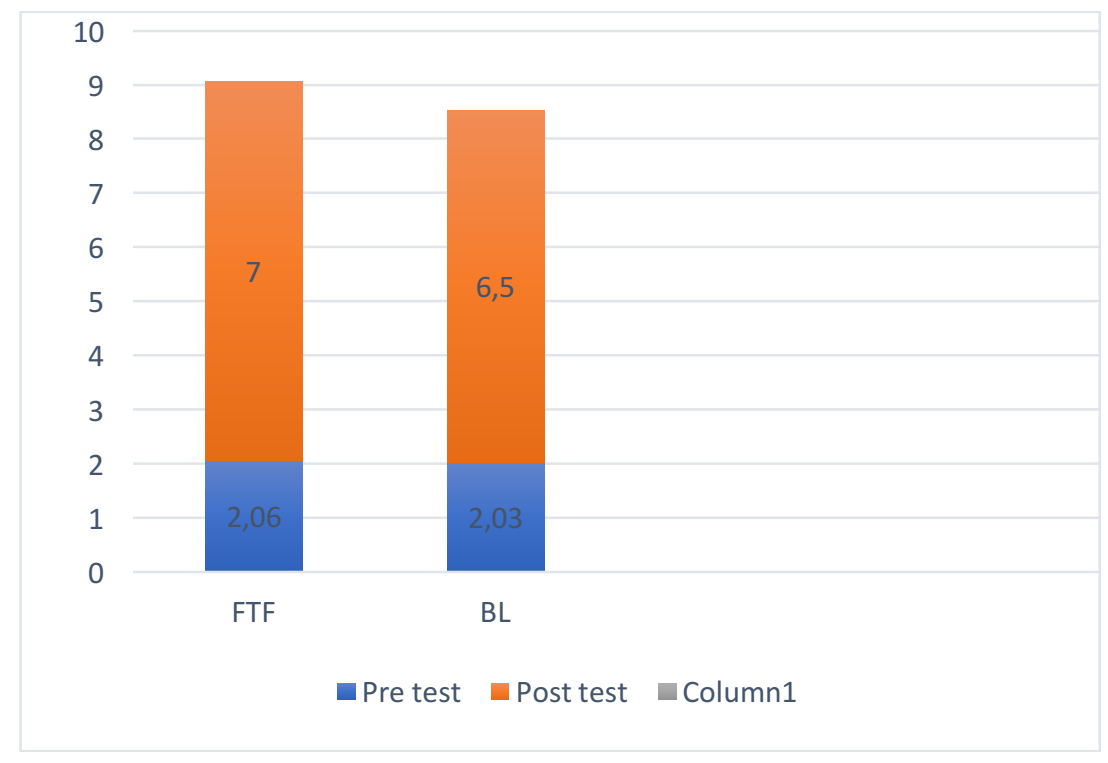

Figure 1. Means of the pre and post-level of the performance for the control (FTF) and experimental (BL) groups

Finally, no significant differences occurred in the level of performance between the control and experimental groups in the post-test, as shown in Table 4, Figure 2. Thus, we accept the null hypothesis.

Table 4. Mean, standard deviation, and t-test for the post-test for the level of performance the control (FTF) and experimental (BL) groups.

\begin{tabular}{cccccc}
\hline \multirow{3}{*}{ Level of Performance } & Group & Mean & SD & t-Test & sig \\
\cline { 2 - 6 } & FTF & 7 & 1.14 & \multirow{2}{*}{1.69} & .09 \\
\hline
\end{tabular}

Note. ${ }^{*} p<.05$

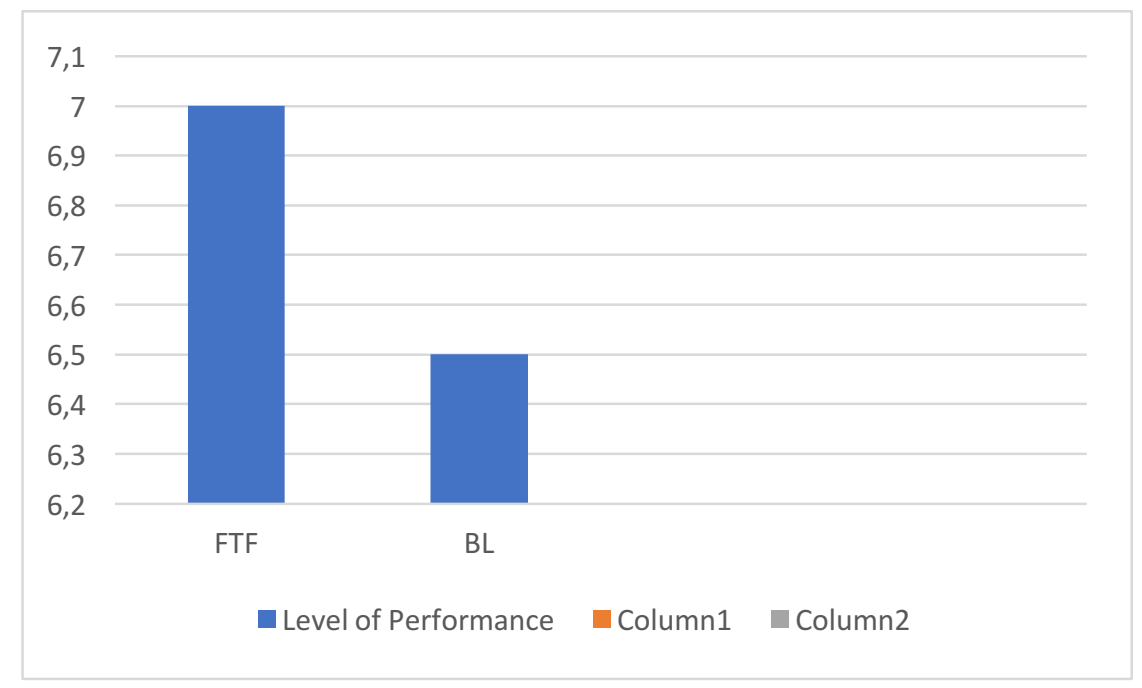

Figure 2. Means of the post-test for the level of performance the control (FTF) and experimental (BL) groups. 
H02: There is no statistically significant difference between post-test scores of both control (FTF group) and experimental group (BL group) of students' motivation type according to selfdetermination theory at the level of $a \leq 0.05$.

The results of the pre and post-test of the the students' motivation in the control group showed in Table 5 indicate significant differences in their motivation towards sport participation in total and in the subscales of IM - To Know and in the Amotivation in favor of the post-test, whereas no significant differences occur in the rest of the motivation subscales Figure 3.

Table 5. Mean, standard deviation, and t-test for the pre and post-test of the motivation subscales for the control group (FTF).

\begin{tabular}{|c|c|c|c|c|c|}
\hline $\begin{array}{c}\text { Motivation Subscales } \\
\text { FTF }\end{array}$ & Test & Mean & SD & $\mathrm{t}$-Test & sig \\
\hline \multirow[b]{2}{*}{ IM - To Know } & Pre & 3.25 & .62 & \multirow[b]{2}{*}{2.44} & \multirow[b]{2}{*}{$.01^{*}$} \\
\hline & Post & 3.56 & .31 & & \\
\hline \multirow{2}{*}{ IM - To Accomplish } & Pre & 3.48 & .23 & \multirow{2}{*}{1.36} & \multirow{2}{*}{.17} \\
\hline & Post & 3.58 & .33 & & \\
\hline \multirow{2}{*}{ IM - To Experience } & Pre & 3.34 & .51 & \multirow{2}{*}{.66} & \multirow{2}{*}{.51} \\
\hline & Post & 3.42 & 0.42 & & \\
\hline \multirow{2}{*}{ Intrinsic Motivation } & Pre & 3.35 & .30 & \multirow{2}{*}{1.87} & \multirow{2}{*}{.06} \\
\hline & Post & 3.51 & 0.36 & & \\
\hline \multirow{2}{*}{ Identified Regulation } & Pre & 3.55 & .46 & \multirow{2}{*}{0.7} & \multirow{2}{*}{.44} \\
\hline & Post & 3.69 & .89 & & \\
\hline \multirow{2}{*}{ Introjected Regulation } & Pre & 3.63 & .59 & \multirow{2}{*}{.68} & \multirow{2}{*}{.49} \\
\hline & Post & 3.74 & 0.65 & & \\
\hline \multirow{2}{*}{ External Regulation } & Pre & 3.60 & .57 & \multirow{2}{*}{1.58} & \multirow{2}{*}{.11} \\
\hline & Post & 3.81 & .45 & & \\
\hline \multirow{2}{*}{ Extrinsic Motivation } & Pre & 3.59 & .35 & \multirow{2}{*}{1.88} & \multirow{2}{*}{.06} \\
\hline & Post & 3.32 & 0.7 & & \\
\hline \multirow{2}{*}{ Amotivation } & Pre & 3.29 & .61 & \multirow{2}{*}{2.01} & \multirow{2}{*}{$.04^{*}$} \\
\hline & Post & 2.98 & .53 & & \\
\hline \multirow[t]{2}{*}{ Total } & Pre & 3.31 & .46 & \multirow{2}{*}{2.17} & \multirow{2}{*}{$.000^{*}$} \\
\hline & Post & 3.61 & .60 & & \\
\hline
\end{tabular}

Note. ${ }^{*} p<.05$

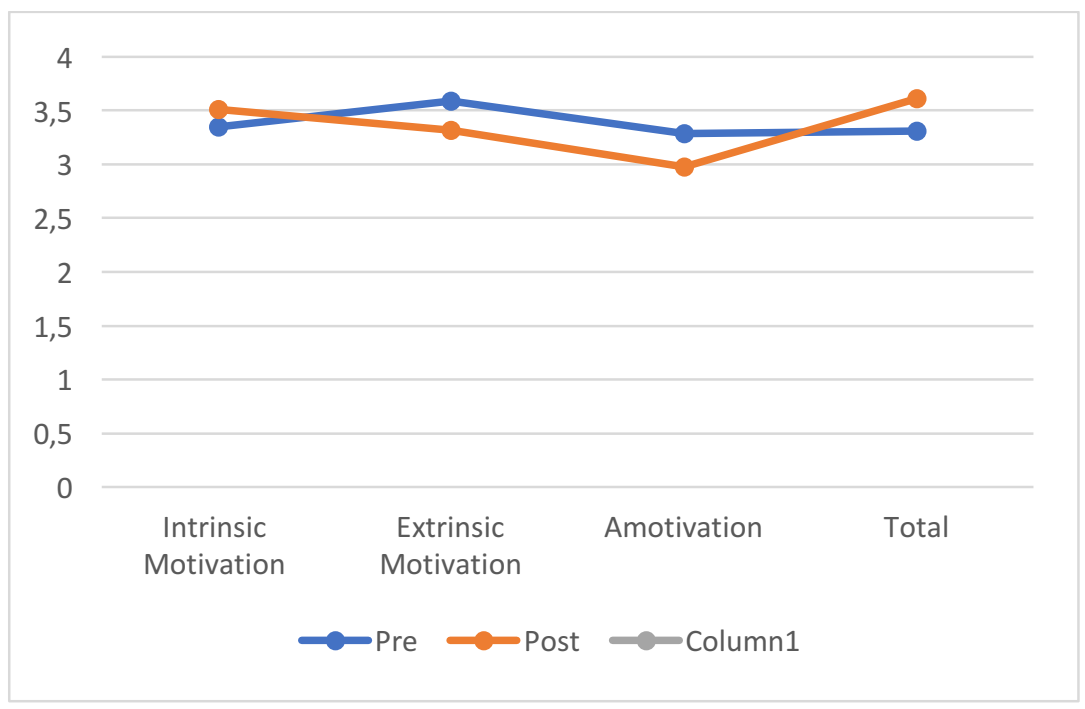

Figure 3. Means of the pre and post-test of the motivation subscales for the control group (FTF) 
Accordingly, Table 6 reveals significant differences all motivation subscales and in the total as well between the pre and post-test in favor of the post-test for the experimental group (BL) Figure 4.

Table 6. Mean, standard deviation, and t-test for the pre and post-test of the motivation subscales for the experimental group (BL).

\begin{tabular}{|c|c|c|c|c|c|}
\hline $\begin{array}{c}\text { Motivation subscales } \\
\text { BL }\end{array}$ & Test & Mean & SD & $\mathrm{t}$-Test & sig \\
\hline \multirow{2}{*}{ IM - To Know } & Pre & 3.33 & .49 & \multirow{2}{*}{12.82} & \multirow{2}{*}{$.000^{*}$} \\
\hline & Post & 5.78 & .94 & & \\
\hline \multirow{2}{*}{ IM - To Accomplish } & Pre & 3.56 & .82 & \multirow[b]{2}{*}{16.25} & \multirow{2}{*}{$.000^{*}$} \\
\hline & Post & 6.16 & .62 & & \\
\hline \multirow{2}{*}{ IM - To Experience } & Pre & 3.29 & 0.56 & \multirow{2}{*}{13.45} & \multirow{2}{*}{$.000^{*}$} \\
\hline & Post & 5.79 & .85 & & \\
\hline \multirow{2}{*}{ Intrinsic Motivation } & Pre & 3.51 & 0.36 & \multirow{2}{*}{16.89} & \multirow{2}{*}{$.000^{*}$} \\
\hline & Post & 5.91 & .69 & & \\
\hline \multirow{2}{*}{ Identified Regulation } & Pre & 3.61 & .86 & \multirow{2}{*}{13.98} & \multirow{2}{*}{$.000^{*}$} \\
\hline & Post & 5.85 & .8 & & \\
\hline \multirow{2}{*}{ Introjected Regulation } & Pre & 3.71 & .68 & \multirow{2}{*}{7.91} & \multirow{2}{*}{$.000^{*}$} \\
\hline & Post & 5.1 & 1.04 & & \\
\hline \multirow{2}{*}{ External Regulation } & Pre & 3.86 & .71 & \multirow{2}{*}{2.88} & \multirow{2}{*}{$.000^{*}$} \\
\hline & Post & 4.7 & 1.43 & & \\
\hline \multirow{2}{*}{ Extrinsic Motivation } & Pre & 3.59 & .35 & \multirow{2}{*}{8.84} & \multirow{2}{*}{$.000^{*}$} \\
\hline & Post & 5.21 & .94 & & \\
\hline \multirow{2}{*}{ Amotivation } & Pre & 3.5 & .65 & \multirow{2}{*}{4.41} & \multirow{2}{*}{$.000^{*}$} \\
\hline & Post & 2.4 & 1.2 & & \\
\hline \multirow{2}{*}{ Total } & Pre & 3.4 & .51 & \multirow[t]{2}{*}{4.25} & \multirow{2}{*}{$.000^{*}$} \\
\hline & Post & 3.89 & .37 & & \\
\hline
\end{tabular}

Note. ${ }^{*} p<.05$

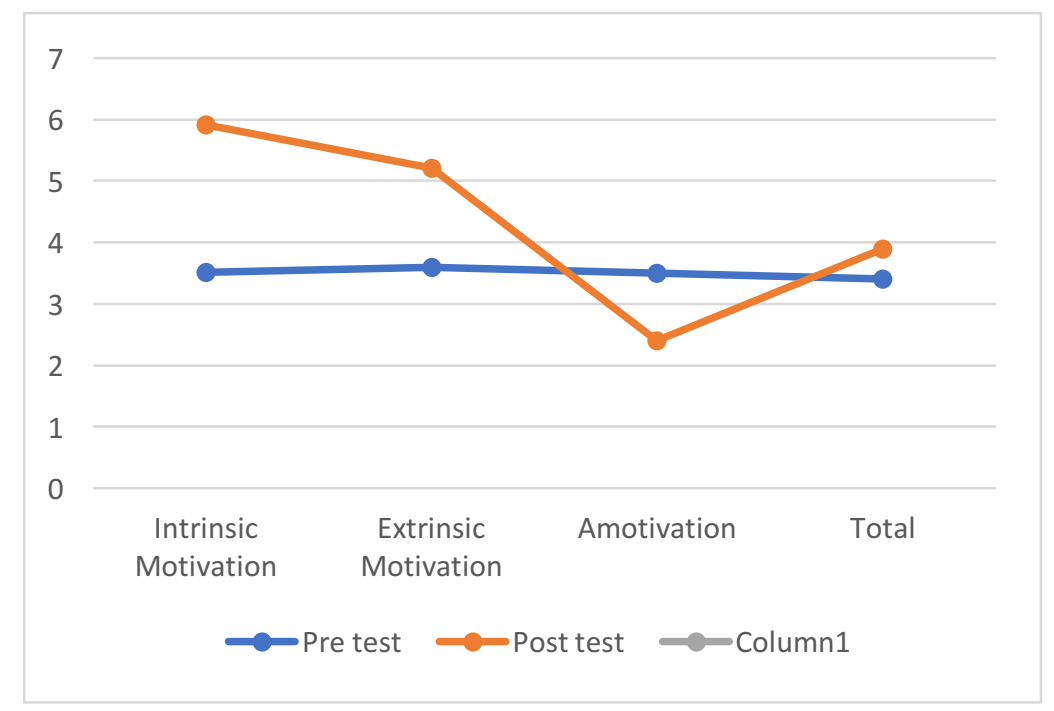

Figure 4. Means of the pre and post-test of the motivation subscales for the experimental group (BL).

Nevertheless, Table 7 showed significant differences between the control and experimental group in the post-tests in total and in all subscales in favor of the experimental group (BL). Except for the Amotivation subscale, which was statistically significant in favor of the control group (FTF) Figure 5. Therefore, we reject the null hypothesis and accept the alternative hypothesis that there is a statistically significant difference between post-test scores of both control (FTF) and experimental group (BL) of students' motivation type according to self-determination theory at the level of $a \leq 0.05$. 
Table 7. Mean, Standard Deviation, and t-test for the post-test of the motivation subscales for the control (FTF) and experimental (BL) groups.

\begin{tabular}{|c|c|c|c|c|c|}
\hline Motivation subscales & Group & Mean & SD & t-Test & sig \\
\hline \multirow{2}{*}{ IM - To Know } & FTF & 3.56 & .31 & \multirow{2}{*}{12.22} & \multirow{2}{*}{$.000^{*}$} \\
\hline & $\mathrm{BL}$ & 5.78 & .94 & & \\
\hline \multirow{2}{*}{ IM - To Accomplish } & FTF & 3.58 & .33 & \multirow{2}{*}{23.04} & \multirow{2}{*}{$.000^{*}$} \\
\hline & $\mathrm{BL}$ & 6.16 & .62 & & \\
\hline \multirow{2}{*}{ IM - To Experience } & FTF & 3.42 & 0.42 & \multirow{2}{*}{13.4} & \multirow{2}{*}{$.000^{*}$} \\
\hline & $\mathrm{BL}$ & 5.79 & .85 & & \\
\hline \multirow{2}{*}{ Intrinsic Motivation } & FTF & 3.51 & 0.36 & \multirow{2}{*}{18.7} & \multirow{2}{*}{$.000^{*}$} \\
\hline & $\mathrm{BL}$ & 5.91 & .69 & & \\
\hline \multirow{2}{*}{ Identified Regulation } & FTF & 3.69 & .89 & \multirow{2}{*}{13.6} & \multirow{2}{*}{$.000^{*}$} \\
\hline & $\mathrm{BL}$ & 5.85 & .8 & & \\
\hline \multirow{2}{*}{ Introjected Regulation } & FTF & 3.63 & .59 & \multirow{2}{*}{7.76} & \multirow{2}{*}{$.000^{*}$} \\
\hline & $B L$ & 5.1 & 1.04 & & \\
\hline \multirow{2}{*}{ External Regulation } & FTF & 3.74 & 0.65 & \multirow{2}{*}{3.89} & \multirow{2}{*}{$.000^{*}$} \\
\hline & $B L$ & 4.7 & 1.43 & & \\
\hline \multirow{2}{*}{ Extrinsic Motivation } & FTF & 3.95 & 0.7 & \multirow{2}{*}{2.76} & \multirow{2}{*}{$.009^{*}$} \\
\hline & $\mathrm{BL}$ & 5.21 & .94 & & \\
\hline \multirow{2}{*}{ Amotivation } & FTF & 2.98 & .53 & \multirow{2}{*}{3.09} & \multirow{2}{*}{$.000^{*}$} \\
\hline & $B L$ & 2.4 & 1.2 & & \\
\hline \multirow{2}{*}{ Total } & FTF & 3.61 & .69 & \multirow{2}{*}{2.17} & \multirow{2}{*}{$.03^{*}$} \\
\hline & $\mathrm{BL}$ & 3.89 & .37 & & \\
\hline
\end{tabular}

Note. ${ }^{*} p<.05$

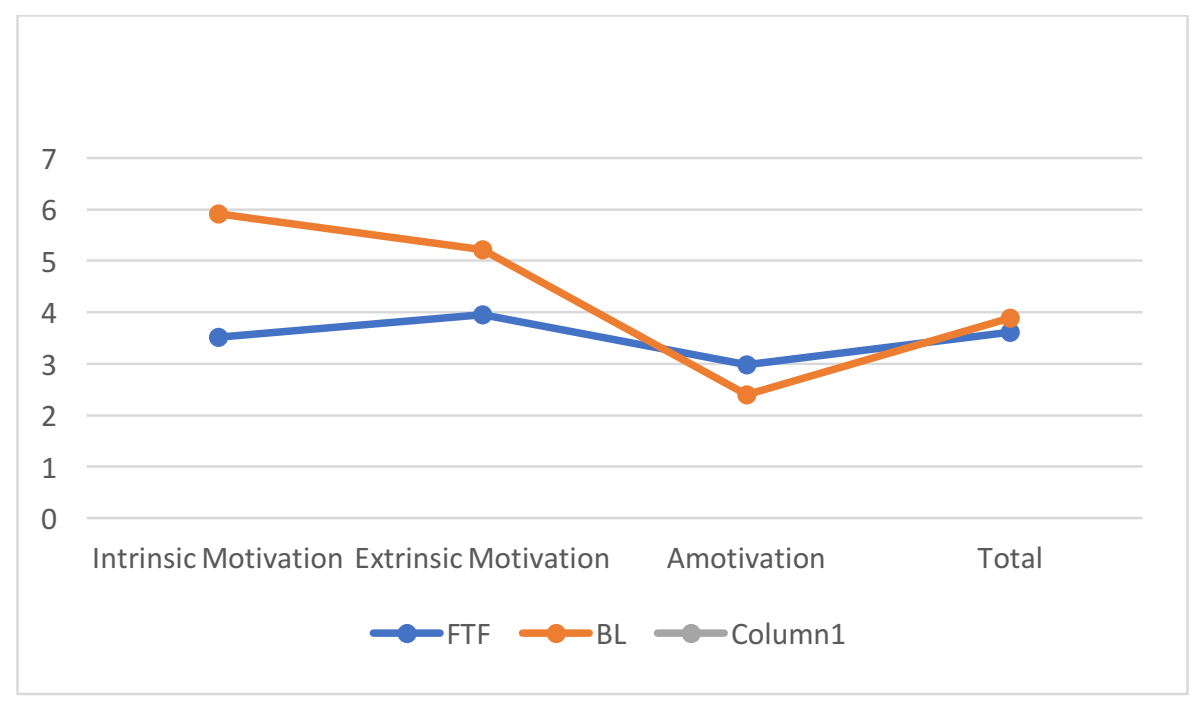

Figure 5. Means of the post-test of the motivation subscales for the control (FTF) and experimental (BL) groups.

\section{DISCUSSIONS}

This study was conducted at the School of Physical Education/the University of Jordan to evaluate and compare the effect of the BL (experimental group) to the conventional teaching method FTF (control group) on students' level of performance and sport participation motivation level.

It seeks to argue that there is no significant difference between the FTF group and the BL group in terms of students' level of performance and students' motivation type according to self-determination theory in ballet skills.

Results of this study revealed no significant differences between teaching strategies in terms of students' level of performance. The BL strategy had the same effect on students' level of performing Ballet skills 
as the traditional FTF course. This is consistent Shen et al. (2007) and Delialioglu and Yildirim (2008) who have found no significant difference in student outcomes and achievement between traditional FTF teaching and technology-delivered instruction. Although the students spend less time in class, they had benefited the online educational sources and practiced in their free time. Students had a flexible time to practice their skills through the links and videos provided for them. These materials help to better support students' differences and preferences Keogh et al., (2017). Students wisely invested their sources, that is because BL is more student-centered. Feng, (2018) emphasized the influence of the learning situation and environment. This finding of no significant difference is also consistent with Russell (1999) who agreed that BL could be considered as successful as FTF learning according to the no significant difference phenomenon he suggested. Students were more satisfied with BL than the FTF as a mode of delivery (Delialioglu and Yildirim, 2008). However, previous literature supports that BL is more effective than FTF teaching method in relation to course achievement; BL can positively promote students' sports performance and efficiency (Feng, 2018). Smith (2005) emphasized that the BL environment provides improved learning outcomes and improved student and faculty satisfaction.

The BL environments increases students' ability to accomplish course objectives compared to the traditional course. Such environment pays more attention to the excavation of sports information resources. These resources help the growth of sports knowledge and evaluate students' physical training levels through diversified evaluation modes (Feng, 2018). Turkcapar, (2015) indicates that the use of the BL approach enhances student achievement in the field of volleyball.

Learning ballet skills is more about practice than learning concepts. Therefore, the students learn these skills by following detailed instructions and steps to reinforce their skills. In contrast In FTF approach, learning time is limited for practicing skills, especially when the classes are crowded. Therefore, the rich environment of the BL approach was compatible with the traditional FTF approach.

Students' individual learning experience determined their views of their sport motivation level. Results of this study indicate significant differences in post-tests between the FTF and BL students' motivation level. All intrinsic and extrinsic motivation subscales in addition to amotivation were significantly different in favor of BL classes.

Ballet classes contain exercises, combinations, and many new movements or small details to learn. Motivated students are eager and excited to learn new skills. Students who are attending BL classes have an added advantage; They have their resources to refer to in just a few clicks away on their computers or their smart phones. It is always available to help them remember and practice the exercises executed in class and more. They can work their skills out between class meetings. They enhance their understanding of beginning ballet technique, review what they studied in class, or prepare for performance testing (Kassing, 2013). Students used the Moodle to communicate through discussion forums with their peers. Thus, it opens new dimensions and thinking patterns. This pattern intrinsically motivates the students to be actively involved in the BL environment. Therefore, the overall intrinsic motivation level is significant and higher in BL classes.

The intrinsic motivation level of the participants is reflected in the scale through three subscales; The Intrinsic Motivation - To Know reflects students' type of engagement in BL classes. BL enhanced students' desire to learn and practice ballet skills. BL methodology is considered as an improved pedagogy that increases students' access to knowledge and learning experiences (Osguthorpe and Graham, 2003). Students are pleased and satisfied with the experience of learning, exploring, or trying to practice new skills (Ryan and Deci, 2000).

The Intrinsic Motivation - To Accomplish in the BL approach reflects students' satisfaction of what they accomplished. The variety of instructional methods applied in blended classes has improved the learning environment (Vaughan, 2007). BL offered the students with a vast variety of both instructional and highperformance level videos. As a result, students are enjoying learning and performing new skills by engaging in BL ballet classes. They are mastering the ballet techniques and can connect the basic movements into an artistic phrase. The students are contented with their accomplishment and achievement (Ryan and Deci, 2000).

Finally, BL classes provided students with opportunities to learn efficiently. Such opportunities increase students' Intrinsic Motivation - To experience. Students are experiencing pleasure, fun, and excitement while learning ballet skills (Ryan and Deci, 2000). BL approach created a positive and productive learning environment as the FTF approach while contributing to the teaching process Afacan, (2016). Computer 
network technology has brought tremendous changes to people's life (Le, 2011). Such technology provided a constructive environment full of educational learning materials such as recorded videos of the targeted skills and YouTubes. It is more convenient for the students to watch a video and analyze it to perform the skills better. Due to the different interactive activities and communication with peers that online courses could offer (Hartnett et al., 2011) have concluded that students engaging in online courses are more intrinsically motivated than FTF students.

Students' extrinsic motivation also are significantly different in favor of the BL group. The Identification Regulation reflects students' belief that engaging in ballet classes contributes in part to their growth and development as a person (Ryan and Deci, 2000). In a beginning ballet class, students learn about ballet technique, ballet as an art form, and themselves (Kassing, 2013). The rich BL environment is full of interactive materials such as instructional videos positively affected students' performance and success (Uzun, \& Senturk, 2010; Le, 2011). In addition to the natural use of multiple modalities, which provides better support for different learning styles among students. Students are free to develop their interest in learning activities. They can control the pace of their learning, selecting suitable materials and managing their times (Vaughan, 2007). Smith (2005) have noticed increased and improved interaction and contact among students in a BL environment.

The Introjection Regulation expresses students need to feel that their level of performance is acceptable by their colleagues and instructor and that they are in good shape. Some students may lack the confidence of standing in front of their peers doing the practice (Wang, \& Wang, 2017). Online activities enabled students to practice what they had learned in the FTF classes without the limitations of time and location. Also, students uploaded their routines on the Moodle; they were able to reflect on their performance and compare them with those of their colleagues. Furthermore, during online group discussions, students obtained individual feedback from different peers (Yang, 2012).

Lastly, students' engagement in ballet courses can also be motivated by External Regulation. They performed ballet skills to receive praise from the instructor or to avoid negative consequences such as criticisms or low grades. Praise or rewards provided to students to raise their motivational level for a particular task are considered as extrinsic motivating factors (Ryan and Deci, 2000). Also, the activities and contentment provided by the module extrinsically motivate the students (Waheed et al., 2016). During online group discussions, students obtained individual feedback from different peers (Yang, 2012).

Overall, ballet classes are the starting point for learning ballet. Attending class is the training constant for all students. The BL class is the force that drives the development of the students in technique to achieve better performance. When students learn ballet, they also learn the language of this specific dance form. Knowing the vocabulary helps you to understand and communicate the many possibilities for combining exercises, steps, and poses into various combinations and pieces of choreography (Kassing, 2013). Waheed et al. (2016) found that BL classes enhance motives for sports participation. They stated that the improved modules of the Moodle platform are undoubtedly useful for students to improve their learning experience and can act as motivators for the users. A significant range of intrinsic and extrinsic motivation at different levels occurred depending on the BL environment (Hartnett et al., 2011).

Again, BL students are significantly less amotivated and more related to ballet classes than their colleagues in the FTF classes. FTF students are neither intrinsically nor extrinsically motivated. They feel incompetent and lack of control. They do not identify any good reasons for continuing to learn and train. Eventually, they may decide to stop practicing ballet (Ryan and Deci, 2000).

\section{CONCLUSION}

In conclusion, despite the novice experience of BL in the University of Jordan, BL approach is already adopted in both theoretical and practical courses in the institution. In this study, BL approach is implemented in Ballet classes at the School of the Physical Education /University of Jordan for the first time in the history of teaching this subject. The main question was whether the BL method is comparable to the traditional (FTF) instruction in relation to their level of performance and students' motivation type for sport participation. Throughout the study, BL classes used technology strategically as a tool to deliver instructional content. 
Results of the study were encouraging; No significant differences revealed between both BL and FTF methods in relation to the level of ballet skills. On the other hand, the BL group were more motivated than their peers in the FTF group.

BL proved to be an efficient and convenient methodology in transferring activities online to acquire new abilities. Such results encourage educators to implement BL in their teaching and design motivational BL courses for their students.

\section{LIMITATIONS AND FURTHER RESEARCH}

The results of this study can only be generalized to the population of the School of Physical Education/ University of Jordan. Future research can explore other dimensions in different theoretical and practical courses, cultures, and societies. Study of larger sample size can also be an extension of this study.

\section{BIODATA and CONTACT ADDRESSES of AUTHOR}

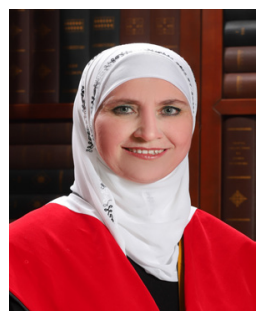

Dr. Manal BAYYAT, is an Assistant Professor of Sport Psychology, Life Skills, Fencing and Ballet at the School of Physical Education, University of Jordan. Dr. Bayyat gained her Ph.D. in Physical Education at 2015. Her academic interest areas are learning analytics, sport psychological analytics, social work, blended learning, cyber behaviors and use of internet in education. She has over than 12 journal articles published in international indexes. She participated in several national and international meetings in which her papers where submitted.

\section{Manal BAYYAT}

School of Physical Education

Address: University of Jordan, Postal Code 11942, Amman, Jordan

Phone: +962790354435

E-mail:mabayyat@yahoo.com/m.bayyat@ju.edu.jo

\section{REFERENCES}

Afacan, Y. (2016). Exploring the effectiveness of BL in interior design education. Innovations in Education and Teaching International, 53(5), 508-518.

Ballet. (n.d.). Retrieved April 12, 2018, from https://www.merriam-webster.com/dictionary/ballet

Bayyat, M. M., Almoghrabi, A. H., \& Ay, K. M. (2016). Preliminary validation of an Arabic version of the Sport Motivation Scale (SMS-28). Asian Social Science, 12(7), 186-196.

Brief on Higher Education Sector in Jordan. (2019). Retrieved February 22, 2019, from http://www.mohe. gov.jo/en/pages/BriefMohe1.aspx

Bonk, C. J., Olson, T. M., Wisher, R. A., \& Orvis, K. L. (2002). Learning from focus groups: An examination of BL. International Journal of E-Learning \& Distance Education, 17(3), 97-118.

Bourne, J., Harris, D., \& Mayadas, F. (2005). Online engineering education: Learning anywhere, anytime. Journal of Engineering Education, 94, 131-146.

Dalsgaard, C., \& Godsk, M. (2007). Transforming traditional lectures into problem-based BL: challenges and experiences. Open learning, 22(1), 29-42.

Delialioglu, O., \& Yildirim, Z. (2008). Design and development of a technology-enhanced hybrid instruction based on MOLTA model: Its effectiveness in comparison to traditional instruction. Computers and Education, 51, 474-483.

Dos, B. (2014). Developing and evaluating a BL course. The Anthropologist, 17(1), 121-128.

Feng, S. (2018). Applied Research on College Sports BL Based on Moodle Platform. Educational Sciences: Theory \& Practice, 18(5). 
George-Walker, L. D., \& Keeffe, M. (2010). Self-determined BL: a case study of BL design. Higher Education Research \& Development, 29(1), 1-13.

Güzer, B., \& Caner, H. (2014). The past, present, and future of BL: an in-depth analysis of literature. Procedia-social and behavioral sciences, 116, 4596-4603.

Hartnett, M., George, A. S., \& Dron, J. (2011). Examining motivation in online distance learning environments: Complex, multifaceted, and situation-dependent. The International Review of Research in Open and Distributed Learning, 12(6), 20-38.

Hughes, G. (2007). Using BL to increase learner support and improve retention. Teaching in Higher Education, 12(3), 349-363.

Kassing, G. (2013). Beginning ballet with web resource. Leeds: Human Kinetics.

Keogh, J. W., Gowthorp, L., \& McLean, M. (2017). Perceptions of sport science students on the potential applications and limitations of BL in their education: a qualitative study. Sports biomechanics, 16(3), 297-312.

Khoury, K., Martin, R., \& Rowe, N. (2013). Bursting bubbles between sand and sea: Teaching dance on the edge of the Mediterranean. Research in Dance Education, 14(3), 187-200.

Le, Y. (2011). Application of computer and multimedia technology in college physical education. Circuits, Communications \& System, 1-3.

Li, K., \& Wei, Y. (2011). The investigation and research on the education reform concerning the common volleyball course in the Institute of physical education. Biometrics, 67(2), 331-43.

Magnenat-Thalmann, N., Protopsaltou, D., \& Kavakli, E. (2007, August). Learning how to dance using a web 3D platform. In International Conference on Web-Based Learning (pp. 1-12). Springer, Berlin, Heidelberg.

Mitchell, P., \& Forer, P. (2010). BL: The perceptions of first-year geography students. Journal of Geography in Higher Education, 34(1), 77-89.

Ntoumanis, N. A. (2001). Self-Determination approach to the understanding of motivation in the physical domain. British Journal of Educational Psychology, 71, 225-242.

Osguthorpe, R. T., \& Graham, C. R. (2003). BL environments: Definitions and directions. Quarterly review of distance education, 4(3), 227-33.

Pizzi, M. A. (2014). BL pedagogy: the time is now!. Occupational therapy in health care, 28(3), 333-338.

Russell, T. (1999). The no significant difference phenomenon. Chapel Hill: North Carolina State University.

Ryan, R. M., \& Deci, E. L. (2000). Intrinsic and extrinsic motivations: Classic definitions and new directions. Contemporary educational psychology, 25(1), 54-67.

Schunck, D. H., Pintrich, P., R. \& Meece, J. L., (2008). Motivation in Education (3rd ed.). Upper Saddle River, NJ: Pearson Merill Prentice Hall.

Shen, Q., Chung, J. K., Challis, D., \& Cheung, R. C. (2007). A comparative study of student performance in traditional mode and online mode of learning. Computer Applications in Engineering Education, 15(1), 30-40.

Smith, S. (2005). The positive and challenging aspects of learning online and in traditional face-to-face classrooms: A student perspective. Journal of Special Education Technology (20), 52-59.

Stubbs, M., Martin, I., \& Endlar, L. (2006). The structuration of BL: putting holistic design principles into practice. British Journal of Educational Technology, 37(2), 163-175.

Shroff, R. H., \& Vogel, D. R. (2009). Assessing the factors deemed to support individual student intrinsic motivation in technology-supported online and face-to-face discussions. Journal of Information Technology Education: Research, 8, 59-85. 
Tamim, R. M. (2018). BL for Learner Empowerment: Voices from the Middle East. Journal of Research on Technology in Education, 50(1), 70-83.

Turkcapar, U. (2015). Effects of Web-supported Learning on the Students' Academic Achievement and Selfesteem. The Anthropologist, 21(3), 535-541.

Umino, B., Longstaff, J. S., \& Soga, A. (2009). Feasibility study for ballet e-learning: automatic composition system for ballet enchaînement with online 3D motion data archive. Research in Dance Education, 10(1), 17-32.

Uzun, A., \& Senturk, A., (2010). Blending makes the difference: Comparison of blended and traditional instruction on students' performance and attitudes in computer literacy. Contemporary Educational Technology, 1(3), 196-207.

Vaughan, N., (2007). Perspectives on BL in higher education. International Journal on E-learning, 6(1), 8194.

Waheed, M., Kaur, K., Ain, N., \& Hussain, N. (2016). Perceived learning outcomes from Moodle: An empirical study of intrinsic and extrinsic motivating factors. Information Development, 32(4), $1001-1013$.

Wang, C., \& Wang, S. J., (2017). Relevé: An at-home ballet self-learning interactive system. KnE Engineering, 2(2), 242-248.

Weinberg, R. S., \& Gould, D. (2011). Foundations of Sport and Exercise Psychology (5th ed.). United States: Human Kinetics.

Yang, Y. F., (2012). BL for college students with English reading difficulties. Computer Assisted Language Learning, 25(5), 393-410.

Zhou, Y., Zhou, Y., \& Zhou, Y. (2017). Design of moodle-based podcast teaching platform for the course of aerobic gymnastics. International Journal of Emerging Technologies in Learning, 12(9), 95-104. 


\section{APPENDIX}

The Mid-Term Exam

\begin{tabular}{|c|c|c|c|c|}
\hline & Skills & $\begin{array}{c}\text { Excellent performance } \\
2\end{array}$ & $\begin{array}{c}\text { adequate performance } \\
1\end{array}$ & $\begin{array}{c}\text { Needs improvement } \\
0\end{array}$ \\
\hline 1. & $\begin{array}{l}\text { Arm positions } \\
\text { First position }\end{array}$ & & & \\
\hline 2. & Second position & & & \\
\hline 3. & Third position & & & \\
\hline 4. & Fourth position & & & \\
\hline 5. & Fifth position & & & \\
\hline 6. & $\begin{array}{l}\text { Feet positions } \\
\text { First position }\end{array}$ & & & \\
\hline 7. & Second position & & & \\
\hline 8. & Third position & & & \\
\hline 9. & Fourth position & & & \\
\hline 10 & Fifth position & & & \\
\hline 11. & Demi plie & & & \\
\hline 12. & Pointe tendu & & & \\
\hline 13. & Battement tendu & & & \\
\hline 14. & Releve & & & \\
\hline 15. & Saute & & & \\
\hline 16. & Reverence & & & \\
\hline & Total & & & \\
\hline
\end{tabular}

The Final Exam

\begin{tabular}{|c|l|c|c|c|c|}
\hline & \multicolumn{1}{|c|}{$\begin{array}{c}\text { Skill/ } \\
\text { Performance }\end{array}$} & Creative & $\begin{array}{c}\text { Excellent } \\
\text { performance }\end{array}$ & $\begin{array}{c}\text { adequate } \\
\text { performance } \\
\mathbf{2}\end{array}$ & $\begin{array}{c}\text { Needs } \\
\text { improvement } \\
0\end{array}$ \\
\hline 1. & Phraseology & & & & \\
\hline 2. & Technical skills & & & & \\
\hline 3. & Performance skills & & & & \\
\hline 4. & Rhythm/tempo & & & & \\
\hline 5. & $\begin{array}{l}\text { Use of Space and } \\
\text { Levels }\end{array}$ & & & & \\
\hline 6. & Appearance & & & & \\
\hline
\end{tabular}

